OPEN ACCESS

Edited by:

Christopher Cvitanovic, Australian National University, Australia

Reviewed by: Ella-Kari Muhl,

University of Waterloo, Canada

Georgina Gurney,

ARC Centre of Excellence for Coral

Reef Studies, Australia

*Correspondence:

Megan N. Wilson

wilsomeg@oregonstate.edu

Specialty section:

This article was submitted to

Ocean Solutions,

a section of the journal

Frontiers in Marine Science

Received: 07 August 2020

Accepted: 18 December 2020

Published: 14 January 2021

Citation:

Wilson MN, Laufer $A E$

Howard EM and Wong-Ala JATK (2021) Lessons From the Trenches: Students' Perspectives of Their Own

Marine Transdisciplinary Education.

Front. Mar. Sci. 7:592368.

doi: 10.3389/fmars.2020.592368

\section{Lessons From the Trenches: Students' Perspectives of Their Own Marine Transdisciplinary Education}

\author{
Megan N. Wilson ${ }^{1 *}$, Adrian E. Laufer ${ }^{2,3}$, Erin M. Howard ${ }^{4}$ and Jennifer A. T. K. Wong-Ala ${ }^{5}$ \\ ${ }^{1}$ Integrative Biology Department, Oregon State University, Corvallis, OR, United States, ${ }^{2}$ School of Public Policy, Oregon \\ State University, Corvallis, OR, United States, ${ }^{3}$ Oregon Coastal Management Program, Department of Land Conservation \\ and Development, Salem, OR, United States, ${ }^{4}$ Statistics Department, Oregon State University, Corvallis, OR, United States, \\ ${ }^{5}$ College of Earth, Ocean, and Atmospheric Sciences, Oregon State University, Corvallis, OR, United States
}

Recent environmental changes have demonstrated that the Earth has entered the Anthropocene. In this new age, complex interactions between human and natural systems exacerbate "wicked problems" that challenge researchers to engage both deep disciplinary expertise and broad integrative knowledge to address these societally relevant problems. Researchers and practitioners are making an increased effort to bridge the divide between human and natural systems research by facilitating multi-, inter-, and transdisciplinary collaborations. Despite 21 st century changes to the research environment, the structure of a typical graduate education remains largely unchanged over the past several decades. Wicked problems necessitate communication and collaboration expertise; innovative transdisciplinary training and research opportunities can equip graduate students with these necessary skills. Oregon State University has offered such an opportunity through an NSF-funded Research Traineeship Program (NRT) for students focusing on Risk and Uncertainty Quantification and Communication in Marine Science. Herein, we reflect on the experience of graduate students who successfully completed the NRT and assert that support for transdisciplinary training and research at the graduate stage is urgently needed. We present five lessons learned from our year-long transdisciplinary project focused on the development of an approach for integrating diverse data sets within a social-ecological systems framework to reach a broader understanding of the interconnections between a marine reserve system, people, and the environment. Finally, we present current challenges and paths forward to enhance the success of early career transdisciplinary research.

Keywords: social-ecological systems (SES), graduate education, wicked problems, transdisciplinary training, marine reserves, qualitative network analysis

\section{INTRODUCTION}

Growing populations, large-scale industrialization, increased consumption, and globalization of human systems have drastically altered interconnections between society and the environment. These changes have given rise to the Anthropocene, characterized by global, human-caused environmental changes (Lewis and Maslin, 2015). Complex interconnections currently span 
multiple scales and systems, intensifying wicked problems: persistent issues that span multiple dimensions (e.g., environment, economics, and human activity), and require collaborative problem-solving (Rittel and Webber, 1973; Jentoft and Chuenpagdee, 2009). The marine environment is rife with wicked problems due to an incomplete understanding of the interconnections between highly dynamic dimensions (e.g., a variable and changing ocean, limited resource pool, and multiple user/knowledge holder groups). Many examples of these wicked problems are globally recognized for their complexity, and include the threats of ocean acidification, prevalence of microplastics, and the sustainability of fisheries (United Nations (UN), 2015).

Traditional disciplinary methods provide a one-dimensional understanding of these complex challenges; this limited perspective is often insufficient to develop effective societal solutions. Therefore, applied scientists, managers, and policymakers are increasingly focused on coordinating collaborative strategies that align multiple knowledge systems at the intersection of multiple dimensions (Blickley et al., 2013). Despite the clear and urgent need for boundary-crossing research, most graduate programs continue to focus on developing deep disciplinary expertise (Ciannelli et al., 2014). As a result, graduate students often lack the necessary skills to integrate across different disciplines and knowledge types, collaborate with non-academics, and pursue diverse career paths (Campbell et al., 2005). A recent report on the status of science, technology, engineering, and mathematics graduate education identified that graduate students are increasingly interested in pursuing careers outside of academia (e.g., government, policy) or working beyond disciplinary interfaces but are lacking the necessary collaboration and communication skills (Cyranoski et al., 2011; Alberts et al., 2014; National Academies of Sciences, Engineering, and Medicine (NASEM), 2018).

In this context, we present the experiences of four graduate students who participated in a National Science Foundation transdisciplinary research traineeship program at Oregon State University (OSU). Our team consisted of four graduate students representing disciplinary expertise in ecology, statistics, public policy, and fisheries oceanography. Though each student brought a different perspective to the team (e.g., personal biases, educational background, career path, and degree timeline), we reflected on the context in which we each came to the project and identified the shared vision of incorporating transdisciplinary processes into our dissertations, theses, and future careers. Our experiences illustrate the benefits of early exposure to transdisciplinary research and provide suggestions for the continued implementation of transdisciplinary programs, both of which are necessary to solve wicked problems. In the paper, we summarize differences between disciplinary, multi-, inter-, and transdisciplinary research, present five lessons learned along our path to transdisciplinarity, and reflect on two challenges that underscore the importance of collaboration and communication training. We hope that sharing these experiences will reduce obstacles for future transdisciplinary endeavors, especially those focused on human-natural systems in marine environments.

\section{A SPECTRUM OF INTEGRATION}

Variation in the amount of integration across dimensions exists on a spectrum ranging from disciplinary to transdisciplinary research (Klein, 1990; Rosenfield, 1992). Literature outlines four distinct levels of collaboration along this spectrum: disciplinary, multidisciplinary, interdisciplinary, and transdisciplinary (Table 1; Klein, 2014). We define transdisciplinary research as different academic disciplines working together with nonacademic collaborators (e.g., stakeholders, practitioners, and tribal nations resource managers) to integrate knowledge and methods to develop and accomplish co-created research goals under one unified conceptual framework (drawing from Stember, 1991; Rosenfield, 1992; Tress et al., 2005; Lang et al., 2012; Mauser et al., 2013; Ciannelli et al., 2014; Kelly et al., 2019). Transdisciplinarity is particularly useful to a research process when the goal is to solve complex or "real-world" problems (Stokols, 2014; Lemos et al., 2018). Additionally, transdisciplinary collaboration may increase in importance as recent societal disruptions impose novel challenges to graduate degree requirements (e.g., COVID-19; Pardo et al., 2020).

\section{TRANSDISCIPLINARY TRAINING FOR GRADUATE STUDENTS}

Oregon State University was awarded a grant through the National Science Foundation Research Traineeship Program (hereafter called the NRT) to support transdisciplinary graduate education, facilitate collaborative research, and explore "Risk and Uncertainty Quantification and Communication in Marine Sciences." The NRT aims to engage graduate students in education, professional experiences, and research to address wicked problems in marine systems. Each academic year, the NRT faculty select graduate students who have been in an existing academic program for at least 1 year, and place them, based on their research interests, into transdisciplinary research teams. These teams participate in a year-long training program composed of four elements: (1) an intensive field course, (2) a graduate specialization in risk and uncertainty, (3) an internship, and (4) a collaborative research project culminating in a transdisciplinary report (authored by all the students in the group) and individual interdisciplinary thesis chapters. Training components are centered on three core concepts that are used to characterize wicked problems in the marine environment: Risk and Uncertainty, Big Data, and Coupled Human-Natural Systems.

The NRT recognizes that navigating the pathway to transdisciplinarity is challenging and takes specific action to minimize barriers (Andrews et al., 2020). The research project and the internship facilitate experiential learning and are valuable opportunities for students to develop new skills, build confidence, and make professional connections that support their future career goals. Additionally, the NRT connects graduate students to mentors with diverse interests, disciplines, and identities. For graduate students, especially those interested in interdisciplinary research, a successful education depends 
TABLE 1 | Spectrum of integration across disciplinary, multi-, inter-, and transdisciplinary collaboration with associated definitions, supporting references, and examples.

\begin{tabular}{|c|c|c|c|c|}
\hline Level of collaboration & Definition & References & Level of Integration & Example \\
\hline Disciplinary & $\begin{array}{l}\text { Research conducted in one } \\
\text { field of study }\end{array}$ & $\begin{array}{l}\text { Rosenfield, 1992; Stokols et al., } \\
2008\end{array}$ & None & $\begin{array}{l}\text { A fisheries stock assessment } \\
\text { that relies solely on the } \\
\text { biological information about the } \\
\text { species }\end{array}$ \\
\hline Multidisciplinary & $\begin{array}{l}\text { Collaboration between } \\
\text { researchers from various } \\
\text { disciplines to work in parallel on } \\
\text { a shared problem }\end{array}$ & $\begin{array}{l}\text { Rosenfield, 1992; Stokols et al., } \\
\text { 2008; Disis and Slattery, } 2010\end{array}$ & $\begin{array}{l}\text { None or weak/temporary } \\
\text { combination of disciplinary } \\
\text { contributions }\end{array}$ & $\begin{array}{l}\text { A fisheries assessment led by a } \\
\text { multidisciplinary committee that } \\
\text { has an explicit requirement for } \\
\text { sociological and economic } \\
\text { input from the outset }\end{array}$ \\
\hline Interdisciplinary & $\begin{array}{l}\text { Researchers from various } \\
\text { disciplines collaborate and } \\
\text { exchange ideas extensively to } \\
\text { meet shared research goals } \\
\text { and achieve a real synthesis of } \\
\text { approaches }\end{array}$ & $\begin{array}{l}\text { Klein, 1990; Stember, 1991; } \\
\text { Tress et al., 2005; Christie, } \\
\text { 2011; Clark et al., 2011; } \\
\text { O'Rourke et al., 2019; Andrews } \\
\text { et al., } 2020\end{array}$ & $\begin{array}{l}\text { Integrate knowledge types, } \\
\text { theories, skill sets, and } \\
\text { methods across disciplines }\end{array}$ & $\begin{array}{l}\text { Fisheries scientists working with } \\
\text { fishing communities, industries, } \\
\text { and management agencies to } \\
\text { situate problems and propose } \\
\text { solutions in dynamic social, } \\
\text { cultural, economic, and political } \\
\text { contexts of change }\end{array}$ \\
\hline Transdisciplinary & $\begin{array}{l}\text { Different academic disciplines } \\
\text { working together with } \\
\text { non-academic collaborators } \\
\text { (e.g., stakeholders, } \\
\text { practitioners, tribal nations } \\
\text { resource managers) to develop } \\
\text { and accomplish co-created } \\
\text { research goals under one } \\
\text { unified conceptual framework }\end{array}$ & $\begin{array}{l}\text { Stember, 1991; Rosenfield, } \\
\text { 1992; Tress et al., 2005; Lang } \\
\text { et al., 2012; Mauser et al., } \\
\text { 2013; Ciannelli et al., 2014; } \\
\text { Kelly et al., } 2019\end{array}$ & $\begin{array}{l}\text { Integrate knowledge types, } \\
\text { theories, skills sets, and } \\
\text { methods among researchers } \\
\text { and practitioners }\end{array}$ & $\begin{array}{l}\text { The process of developing a } \\
\text { decision support tool for a } \\
\text { fishery, where knowledge was } \\
\text { drawn from fisheries scientists, } \\
\text { social scientists, fishing industry } \\
\text { representatives, and federal, } \\
\text { state, and tribal resource } \\
\text { managers }\end{array}$ \\
\hline
\end{tabular}

on the student-faculty relationship (Ellis, 1992; Andrews et al., 2020), and the most effective mentors have experiences in diverse contexts and relationships (Thomas et al., 2007). NRT students are supported by all faculty members engaged in the program, representing over 20 subdisciplines and a variety of career paths.

\section{THE NRT IN RETROSPECT}

Our team was initially assigned with integrating data from ecological, human, and oceanographic dimensions to holistically explore the effects of marine protected areas (MPAs) on ecosystems and communities. An MPA is a clearly defined geographical space, recognized, dedicated, and managed to achieve the long-term conservation of nature with associated ecosystem services and cultural values (IUCN WCPA, 2018). Beginning in 2012, Oregon has been implementing MPAs as part of the coastal management strategy. To study these areas, we collaborated with the Oregon Department of Fish and Wildlife Marine Reserves Program (MRP), a state agency who manages Oregon's 11 MPAs. We focused on the five MPAs that prohibit all development and extraction; these are considered fully protected and are hereafter referred to as marine reserves (Lubchenco and Grorud-Colvert, 2015). The goals of Oregon's marine reserve system are threefold: (1) to conserve marine habitats and biodiversity, (2) to serve as scientific reference sites, and (3) to avoid adverse impact to ocean users and coastal communities (Oregon Ocean Policy Advisory Council, 2008). To meet these goals, the MRP employs a variety of scientific tools to monitor the ecological, human, and oceanographic dimensions of the reserve system over time. Marine reserves are dynamic systems that exist at the intersection of ecology, policy, social science, oceanography, and economics, necessitating that our team take an approach that incorporates multiple perspectives and transcends disciplinary boundaries. In our team's partnership with the MRP, we sought to define mutually informative research questions, to develop an approach that could be used to integrate diverse data sets, and ultimately, to contribute to a broader understanding of the interconnections between the marine reserve system, people, and the environment. We achieve this through the development of three tools: a social-ecological system (SES) framework specific to the Oregon marine reserve system, exploratory data visualization of broad trends, and a flexible modeling tool for complex interactions. In this section, we highlight key lessons learned through this transdisciplinary process (Table 2).

\section{Lesson \#1: Appreciate Process and Retain Flexibility in Outcomes and Products}

Many research environments strongly emphasize end-products (e.g., peer-reviewed publications; Goring et al., 2014). In contrast, the structure of the NRT placed emphasis on training and process and provided funding and support for flexible outcomes. This shift in focus is a key enabling condition for transdisciplinary processes (Lang et al., 2012; Angelstam et al., 2013; Brandt et al., 2013); it allowed our team to experiment with different research approaches before agreeing upon research goals and meaningful outcomes. For example, at an advanced stage of our project we recognized that data limitations and system complexities weakened the strength of our methodological approach. Additionally, our team's partnership with a state agency required mutual investment in relationship-building, 
TABLE 2 | Benefits, challenges, and supporting practices for five key lessons learned during a year-long, student-led transdisciplinary research project.

\begin{tabular}{|c|c|c|c|c|}
\hline \multirow[t]{6}{*}{ Lesson } & & Benefits & Challenges & Supporting practices \\
\hline & $\begin{array}{l}\text { Appreciate process and retain } \\
\text { flexibility in outcomes and } \\
\text { products. }\end{array}$ & $\begin{array}{l}\text { - Focus on integrating across } \\
\text { multiple dimensions, engage } \\
\text { with practitioners, maintain } \\
\text { societal relevance } \\
\text { - Build lasting relationships }\end{array}$ & $\begin{array}{l}\text { - Institutional focus on } \\
\text { end-products } \\
\text { - Securing funding for projects } \\
\text { with flexible timelines } \\
\text { - Relationship building is time } \\
\text { consuming }\end{array}$ & $\begin{array}{l}\text { - Institutional rewards for } \\
\text { process development } \\
\text { - Training-focused programs } \\
\text { - Support timeline flexibility } \\
\text { - Develop communication } \\
\text { competencies } \\
\text { - Develop team culture and } \\
\text { identity }\end{array}$ \\
\hline & $\begin{array}{l}\text { Shared conceptual frameworks } \\
\text { inspire meaningful } \\
\text { communication and integration. }\end{array}$ & $\begin{array}{l}\text { - Align diverse data sets } \\
\text { - Identify and investigate novel } \\
\text { interconnections } \\
\text { - Inform future data collection } \\
\text { - Co-create research questions } \\
\text { with practitioners }\end{array}$ & $\begin{array}{l}\text { - Multiple types of knowledge, } \\
\text { experience, evidence, and data } \\
\text { - Relationship building is time } \\
\text { consuming }\end{array}$ & $\begin{array}{l}\text { - Use of boundary objects } \\
\text { - Review and adapt existing } \\
\text { frameworks } \\
\text { - Develop communication } \\
\text { competencies }\end{array}$ \\
\hline & $\begin{array}{l}\text { Exploratory data visualization is } \\
\text { a powerful method for } \\
\text { characterizing broad trends. }\end{array}$ & $\begin{array}{l}\text { - Methodological starting point } \\
\text { - Inform future data collection } \\
\text { and/or research questions } \\
\text { - Elicit multiple perspectives from } \\
\text { researchers and practitioners } \\
\text { - High-level understanding of } \\
\text { system }\end{array}$ & $\begin{array}{l}\text { - Data with multiple temporal } \\
\text { and/or spatial scales } \\
\text { - Many statistical tools may not } \\
\text { be applicable } \\
\text { - May not find statistically } \\
\text { significant evidence } \\
\text { - Iterative, time-intensive process }\end{array}$ & $\begin{array}{l}\text { - Frequent engagement with } \\
\text { practitioners to discuss: } \\
\text { o Scale of questions } \\
\text { o Data aggregation } \\
\text { o Expectations for statistical } \\
\text { evidence }\end{array}$ \\
\hline & $\begin{array}{l}\text { Flexible modeling approaches } \\
\text { are compelling tools to } \\
\text { understand complex } \\
\text { interactions. }\end{array}$ & $\begin{array}{l}\text { - Incorporate multiple data types } \\
\text { and perspectives } \\
\text { - Can have relatively low } \\
\text { computing power } \\
\text { - Can be user friendly } \\
\text { - Simulate several model } \\
\text { structures } \\
\text { - Measure system responses to } \\
\text { simulated perturbation }\end{array}$ & $\begin{array}{l}\text { - Often rely on user assumptions } \\
\text { (e.g., literature review or expert } \\
\text { knowledge) } \\
\text { - Mix of qualitative and } \\
\text { quantitative results }\end{array}$ & $\begin{array}{l}\text { - Practice communication of } \\
\text { results: } \\
\text { o Avoid jargon } \\
\text { o Clarify role of user } \\
\text { assumptions } \\
\text { o Discuss model process and } \\
\text { uncertainty }\end{array}$ \\
\hline & $\begin{array}{l}\text { Maintain relevance for end } \\
\text { users throughout the } \\
\text { transdisciplinary process. }\end{array}$ & $\begin{array}{l}\text { - Balance scientific credibility } \\
\text { with salience and legitimacy to } \\
\text { stakeholders } \\
\text { - Practitioner empowerment }\end{array}$ & $\begin{array}{l}\text { - Reaching consensus about } \\
\text { research process and } \\
\text { application of results is time } \\
\text { consuming }\end{array}$ & $\begin{array}{l}\text { - Communication and } \\
\text { community engagement } \\
\text { training } \\
\text { - Consider audience values and } \\
\text { goals } \\
\text { - Identify methods compatible } \\
\text { with current management } \\
\text { strategies }\end{array}$ \\
\hline
\end{tabular}

References are drawn from 'The NRT in Retrospect' and 'Transdisciplinary Education: Challenges and Paths Forward' sections.

which is often challenged by timelines and processes that differ between academics and practitioners (Brandt et al., 2013). These experiences took time; however, we understood from the outset that the significant value added from our transdisciplinary endeavor lays in the process of drawing from multiple dimensions, engaging with practitioners, and maintaining societal relevance (Lang et al., 2012). We suggest that research modifications and relationship building be viewed not as detours that detract from progress toward a fixed product, but instead as necessary elements of transdisciplinary process, and that timeline flexibility is built in accordingly.

\section{Lesson \#2: Shared Conceptual Frameworks Inspire Meaningful Communication and Integration}

A fundamental challenge of transdisciplinary research is integrating different types of knowledge, experience, evidence, and data to clearly frame a project and co-create research questions with practitioners (Jahn et al., 2012; Lang et al.,
2012). Our team identified that using a shared conceptual framework as a shared point of reference, or boundary object (Gorman, 2002), was key. Because our project focused on the ecological, human dimensions, and oceanographic aspects of marine reserves, we used Ostrom's SES framework (Ostrom, 2009) as the grounding theory and boundary object (as in Gurney et al., 2019) for our work, though many other SES frameworks exist (see review by Binder et al., 2013). Ostrom's framework has been applied to several marine systems (e.g., Cinner et al., 2012; Leslie et al., 2015; Martone et al., 2017; BottoBarrios and Saavedra-Díaz, 2020) and suggests that analyzing the sustainability of an SES requires the description of core subsystems (e.g., Resource Units, Resource System, Governance System, and Users), their interactions, outcomes, and larger ecosystem or socio-political context. Our team coalesced existing data streams from various agencies and institutions (see Lesson \#3: Exploratory data visualization is a powerful method for characterizing broad trends) relevant to the Oregon Marine Reserves SES. Through iterative conversations that transcended each of our epistemologies, we reached consensus about the 
placement of each data stream within the framework. The significance of this process and product lies in the ability to align diverse data sets, investigate novel interconnections, identify areas for future data collection, and co-create research questions with MRP.

\section{Lesson \#3: Exploratory Data Visualization Is a Powerful Method for Characterizing Broad Trends}

Transdisciplinary research commonly encounters different types and spatiotemporal scales of data. Our team utilized several datasets related to the marine reserve system: qualitative and quantitative human dimensions data (e.g., wellbeing), ecological data (e.g., species diversity), and oceanographic data (e.g., temperature). Data were collected on seasonal (e.g., visual surveys), annual (e.g., census), and opportunistic (e.g., workshops) time scales, and at different spatial scales ranging from single locations (e.g., oceanographic moorings) to coastwide (e.g., upwelling). Identifying available features in the data and hypothesizing what relationships may exist can provide a starting point for constructing visualizations. Our team learned that data visualization is an iterative, time-intensive process that facilitates the transdisciplinary process by generating discussion about variable types, spatio-temporal scales, and questions of interest between researchers and practitioners. We found exploratory data visualization to be productive methodological starting point and we propose that it be used as a standardized approach in transdisciplinary research (Brandt et al., 2013).

Many frameworks that evaluate ecological or social change over time require a time-series of predictor and response variables with sufficient replication over space and time to identify statistically significant differences. Our team studied a relatively new marine reserve system with developing monitoring capacity. Marine reserve literature suggested that we should not expect to find statistically significant evidence for change over this time period (Micheli et al., 2004; Babcock et al., 2010; Gill et al., 2017; Nickols et al., 2019). Thus, we focused on high-level integration and asked broad questions (e.g., "What is the effect of the marine reserves system on people and the environment?"). Accordingly, we aggregated data to a high level at the expense of statistical power. We identified broad patterns and trends which were important tools for engaging with experts, eliciting multiple perspectives, and achieving a more holistic understanding of the system. These conversations could then be used to inform future, more specific, research projects where statistically significant evidence is more appropriate. We suggest that transdisciplinary teams dedicate time early in their process to discuss the scale of their questions, appropriate levels of data aggregation, and expectations for statistical evidence with practitioners.

\section{Lesson \#4: Flexible Modeling Approaches Are Compelling Tools to Understand Complex Interactions}

Flexible modeling techniques, such as qualitative network analysis (QNA), are compelling tools for simulating complex interactions, especially in data limited systems (MelbourneThomas et al., 2012; Harvey et al., 2016; Martone et al., 2017). QNA is often used when the data are disparate (e.g., scales are mismatched); thus, user assumptions (e.g., literature review or expert knowledge) inform network characteristics. We developed a hypothetical network where nodes were represented by variables from the ecological, human, and oceanographic dimensions of our SES, and linkages between nodes were informed by literature review. We utilized QNA to simulate interactions in our SES framework by qualitatively measuring the ripple effect of perturbations throughout the network, thereby elucidating system responses.

We recommend that transdisciplinary teams do not overlook flexible modeling tools such as QNA because they can incorporate multiple data types, require relatively low computing power, and can simulate several model structures in real-time. Additionally, user-friendly models provide the unique opportunity to solicit perspectives from different academic disciplines or stakeholder groups and engage in participatory model construction (Kosko, 1986; Gray et al., 2015; Vasslides and Jensen, 2016).

\section{Lesson \#5: Maintain Relevance for End Users Throughout the Transdisciplinary Process}

The past four lessons emerged, in part, from our dedication to maintaining relevance across a wide range of audiences. From the outset of our project, we intended for our findings and products to support marine reserve management. Consideration of our end users shaped our transdisciplinary experience by encouraging us to embrace a flexible process, identify boundary objects, utilize visual communication tools, and apply methods compatible with current management strategies (Lang et al., 2012; Yates et al., 2015; Kelly et al., 2019; Andrews et al., 2020). These processes, tools, and the conversations they evoked helped to balance the scientific credibility of our research with salience and legitimacy in the eyes of practitioners (in this case, the MRP; Cash et al., 2003), as the definition of transdisciplinarity outlines. The significance of this approach lies in practitioner empowerment (Krütli et al., 2010), a central but challenging goal of transdisciplinary science where practitioners are given decisionmaking authority in the research process and application of results (Brandt et al., 2013). Therefore, we suggest that transdisciplinary teams consider their audience's values and goals throughout each step of the research process. Transdisciplinary training programs can support this effort through specialized coursework in science communication and community engagement.

\section{TRANSDISCIPLINARY EDUCATION: CHALLENGES AND PATHS FORWARD}

Our experiences completing the NRT program highlighted two practical challenges that may face future transdisciplinary educators and students. If they are overcome, transdisciplinarity 
is more enjoyable and attainable (Cundill et al., 2019; Kozlowski and Bell, 2019).

\section{Overcoming Disciplinary Differences}

Typically, researchers involved in transdisciplinary collaborations have already developed strong disciplinary expertise rooted in subject matter, specialized language, research orientation, and disciplinary culture (Pohl and Hadorn, 2008; Stone, 2014; Szoslak, 2014). After devoting significant time and mental fortitude to a specific discipline, these factors coalesce to shape an epistemology (Stone, 2014). Embarking on transdisciplinary research forces interactions with differing epistemologies, which can be perceived as uncomfortable, adversarial, or even academically disloyal (Bennett and Gadlin, 2019). True transdisciplinarity requires the consideration and appreciation of disciplinary differences in order to transcend disciplinary boundaries and uncover novel solutions (Stone, 2014). While these feelings may be taxing, this challenge cannot be resisted; instead, the solution is to lean in. Our experiences and prior research suggests that this solution is most effective when team members practice reflection of their own disciplinary biases, remain open to new ideas, and appreciate and compromise around disciplinary differences (Borrego and Newswander, 2010; Szoslak, 2014; Kelly et al., 2019; O’Rourke et al., 2019).

Conscientious communication provides a foundation for exploring disciplinary boundaries. Many researchers and practitioners encounter communication conflicts within their own discipline; transdisciplinary communication presents unique challenges that compound with these conflicts. Past research highlights various communication competencies that promote constructive dialog among a transdisciplinary team: active listening (National Research Council, 2015; Nurius and Kemp, 2019), avoiding jargon (O’Rourke et al., 2019), reflexivity (Thompson, 2009; Read et al., 2016), identifying boundary objects (Gorman, 2002), and optimizing communication technologies (National Research Council, 2015).

\section{Developing Relationships}

Relationship building is a key component of transdisciplinarity because it establishes trust and team cohesion and sets a foundation for the aforementioned communication competencies. With the development of personal relationships comes empathy, understanding, and human connection. Team science literature explains that relationships are created during the forming phase of group development (Tuckman, 1965) and establish a baseline for transdisciplinary interactions. Over time, these deliberate actions create a distinct team culture that persists throughout other stages of team science (Tuckman, 1965; Cheruvelil et al., 2014). Team culture is critical for long-term collaboration because it establishes realistic structure and expectations (Cheruvelil et al., 2014). It also supports a cohesive team identity, which has been positively associated with transdisciplinary team performance (Barsade, 2002; Beal et al., 2003) and negatively associated with team conflict (Bennett and Gadlin, 2019). In our team's experience, building our team culture and identity was a worthwhile time investment, increasing our ability to articulate shared expectations and overcome differences in individual goals and graduate education timeline.

\section{CONCLUSION}

The need for transdisciplinary training and research opportunities during the early stages of graduate education is immediate and unavoidable. Wicked problems are only increasing in magnitude and complexity, and the next generation of marine researchers and practitioners must be equipped with collaborative skills to solve them. The challenges we have addressed in this piece confront current academic structures and are intellectually, emotionally, and financially demanding. Their solutions require flexibility, innovation, and endurance. The NRT program represents one possible solution: expanding the scope of OSU graduate education by building institutional capacity (e.g., specialized courses, connection to diverse mentors, and student funding) to support a transdisciplinary research track. In order to support similar transdisciplinary training opportunities, higher education must adapt to support transdisciplinary education. Our experiences as graduate students illustrate the value gained: we have developed the skills and experience necessary to address wicked problems with a transdisciplinary approach and are now poised to use them in our future careers. Finally, it is our hope that by sharing our lessons learned on the path to transdisciplinarity, we inspire conversation and action toward the advancement of transdisciplinary education and research.

\section{DATA AVAILABILITY STATEMENT}

The original contributions presented in the study are included in the article/supplementary material; further inquiries can be directed to the corresponding author/s.

\section{AUTHOR CONTRIBUTIONS}

All authors designed and conducted the research. MW coordinated the writing effort. All authors edited and contributed with text.

\section{FUNDING}

MW, AL, and EH were supported by an NSF Graduate Research Traineeship (NSF\#1545188) for the 2018-2019 academic year. JW-A was supported by an NSF Graduate Research Fellowship (NSF\#1840998) for the duration of this project.

\section{ACKNOWLEDGMENTS}

We thank the OSU NRT faculty who mentored, advised, and supported our team: Ana K. Spalding, Kirsten GrorudColvert, Lorenzo Ciannelli, and Alix Gitelman. We thank the 
Oregon Department of Fish and Wildlife Marine Reserves Program, specifically Lindsay Aylesworth, Cristen Don, Thomas

\section{REFERENCES}

Alberts, B., Kirschner, M. W., Tilghman, S., and Varmus, H. (2014). Rescuing US biomedical research from its systemic flaws. Proc. Natl. Acad. Sci. U.S.A. 111, 5773-5777. doi: 10.1073/pnas.1404402111

Andrews, E. J., Harper, S., Cashion, T., Palacios-Abrantes, J., Blythe, J., Daly, J., et al. (2020). Supporting early career researchers: insights from interdisciplinary marine scientists. ICES J. Mar. Sci. 77, 476-485. doi: 10.1093/icesjms/fsz247

Angelstam, P., Andersson, K., Annerstedt, M., Axelsson, R., Elbakidze, M., Garrido, P., et al. (2013). Solving problems in social-ecological systems: definition, practice and barriers of transdisciplinary research. Ambio 42, 254-265. doi: 10.1007/s13280-012-0372-4

Babcock, R. C., Shears, N. T., Alcala, A. C., Barrett, N. S., Edgar, G. J., Lafferty, K. D., et al. (2010). Decadal trends in marine reserves reveal differential rates of change in direct and indirect effects. Proc. Natl. Acad. Sci. U.S.A. 107, 18256-18261. doi: 10.1073/pnas.0908012107

Barsade, S. G. (2002). The ripple effect: emotional contagion and its influence on group behavior. Adm. Sci. Q. 47, 644-675. doi: 10.2307/3094912

Beal, D. J., Cohen, R. R., Burke, M. J., and McLendon, C. L. (2003). Cohesion and performance in groups: a meta-analytic clarification of construct relations. J. Appl. Psychol. 88, 989-1004. doi: 10.1037/0021-9010.88.6.989

Bennett, L. M., and Gadlin, H. (2019). "Conflict prevention and management in science teams," in Strategies for Team Science Success, eds K. L. Hall, A. L. Vogel, and R. T. Croyle (Cham: Springer International Publishing), 295-302. doi: 10.1007/978-3-030-20992-6_22

Binder, C. R., Hinkel, J., Bots, P. W. G., and Pahl-Wostl, C. (2013). Comparison of frameworks for analyzing social-ecological systems. Ecol. Soc. 18:26. doi: 10.5751/ES-05551-180426

Blickley, J. L., Deiner, K., Garbach, K., Lacher, I., Meek, M. H., Porensky, L. M., et al. (2013). Graduate student's guide to necessary skills for nonacademic conservation careers. Conserv. Biol. 27, 24-34. doi: 10.1111/j.1523-1739.2012. 01956.x

Borrego, M., and Newswander, L. K. (2010). Definitions of interdisciplinary research: toward graduate-level interdisciplinary learning outcomes. Rev. High. Educ. 34, 61-84. doi: 10.1353/rhe.2010.0006

Botto-Barrios, D., and Saavedra-Díaz, L. (2020). Assessment of Ostrom's socialecological system framework for the comanagement of small-scale marine fisheries in Colombia: from local fishers' perspectives. Ecol. Soc. 25:12.

Brandt, P., Ernst, A., Gralla, F., Luederitz, C., Lang, D. J., Newig, J., et al. (2013). A review of transdisciplinary research in sustainability science. Ecol. Econ. 92, $1-15$.

Campbell, S. P., Fuller, A. K., and Patrick, D. A. (2005). Looking beyond research in doctoral education. Front. Ecol. Environ. 3:153-160. doi: 10.2307/3868543

Cash, D. W., Clark, W. C., Alcock, F., Dickson, N. M., Eckley, N., Guston, D. H., et al. (2003). Knowledge systems for sustainable development. Proc. Natl. Acad. Sci. U.S.A. 100, 8086-8091.

Cheruvelil, K. S., Soranno, P. A., Weathers, K. C., Hanson, P. C., Goring, S. J., Filstrup, C. T., et al. (2014). Creating and maintaining high-performing collaborative research teams: the importance of diversity and interpersonal skills. Front. Ecol. Environ. 12, 31-38. doi: 10.1890/130001

Christie, P. (2011). Creating space for interdisciplinary marine and coastal research: five dilemmas and suggested resolutions. Environ. Conserv. 38, 172186. doi: 10.1017/S0376892911000129

Ciannelli, L., Hunsicker, M., Beaudreau, A., Bailey, K., Crowder, L. B., Finley, C., et al. (2014). Transdisciplinary graduate education in marine resource science and management. ICES J. Mar. Sci. 71, 1047-1051. doi: 10.1093/icesjms/fsu067

Cinner, J. E., McClanahan, T. R., MacNeil, M. A., Graham, N. A., Daw, T. M., Mukminin, A., et al. (2012). Comanagement of coral reef social-ecological systems. Proc. Natl. Acad. Sci. U.S.A. 109, 5219-5222.

Clark, S. G., Steen-Adams, M. M., Pfirman, S., and Wallace, R. L. (2011). Professional development of interdisciplinary environmental scholars. J. Environ. Stud. Sci. 1, 99-113. doi: 10.1007/s13412-011-0018-z

Cundill, G., Harvey, B., Tebboth, M., Cochrane, L., Currie-Alder, B., Vincent, K., et al. (2019). Large-scale transdisciplinary collaboration for adaptation research:
Swearingen, and Justin Ainsworth for discussions, advice, and shared data for this project.

challenges and insights. Glob. Chall. 3:1700132. doi: 10.1002/gch2.20170 0132

Cyranoski, D., Gilbert, N., Ledford, H., Nayar, A., and Yahia, M. (2011). Education: the PhD factory. Nature 472, 276-279. doi: 10.1038/472 276a

Disis, M. L., and Slattery, J. T. (2010). The road we must take: multidisciplinary team science. Sci. Transl. Med. 2, 22cm9-22cm9. doi: 10.1126/scitranslmed. 3000421

Ellis, H. C. (1992). Graduate education in psychology: past, present, and future. Am. Psychol. 7, 570-576. doi: 10.1037/0003-066X.47. 4.570

Gill, D. A., Mascia, M. B., Ahmadia, G. N., Glew, L., Lester, S. E., Barnes, M., et al. (2017). Capacity shortfalls hinder the performance of marine protected areas globally. Nature 543, 665-669. doi: 10.1038/nature21708

Goring, S. J., Weathers, K. C., Dodds, W. K., Soranno, P. A., Sweet, L. C., Cheruvelil, K. S., et al. (2014). Improving the culture of interdisciplinary collaboration in ecology by expanding measures of success. Front. Ecol. Environ. 12:39-47. doi: $10.1890 / 120370$

Gorman, M. E. (2002). Levels of expertise and trading zones: a framework for multidisciplinary collaboration. Soc. Stud. Sci. 32, 933-938. doi: 10.1177/ 030631202128967343

Gray, S., Gray, S., De Kok, J. L., Helfgott, A., O’Dwyer, B., Jordan, R., et al. (2015). Using fuzzy cognitive mapping as a participatory approach to analyze change, preferred states, and perceived resilience of social-ecological systems. Ecol. Soc 20:11. doi: 10.5751/ES-07396-200211

Gurney, G. G., Darling, E. S., Jupiter, S. D., Mangubhai, S., McClanahan, T. R., Lestari, P., et al. (2019). Implementing a social-ecological systems framework for conservation monitoring: lessons from a multi-country coral reef program. Biol. Conserv. 240:108298. doi: 10.1016/j.biocon.2019. 108298

Harvey, C. J., Reum, J. C. P., Poe, M. R., Williams, G. D., and Kim, S. J. (2016). Using conceptual models and qualitative network models to advance integrative assessments of marine ecosystems. Coast. Manage. 44, 486-503. doi: 10.1080/ 08920753.2016.1208881

IUCN WCPA (2018). Applying IUCN's Global Conservation Standards to Marine Protected Areas (MPAs). Delivering Effective Conservation Action through MPAs, to Secure Ocean Health \& Sustainable Development. Version 1.0. Gland: IUCN WCPA.

Jahn, T., Bergmann, M., and Keil, F. (2012). Transdisciplinarity: between mainstreaming and marginalization. Ecol. Econ. 79, 1-10. doi: 10.1016/j. ecolecon.2012.04.017

Jentoft, S., and Chuenpagdee, R. (2009). Fisheries and coastal governance as a wicked problem. Mar. Policy 33, 553-560. doi: 10.1016/j.marpol.2008.12.002

Kelly, R., Mackay, M., Nash, K. L., Cvitanovic, C., Allison, E. H., Armitage, D., et al. (2019). Ten tips for developing interdisciplinary socio-ecological researchers. Socio Ecol. Pract. Res. 1, 149-161. doi: 10.1007/s42532-01900018-2

Klein, J. (2014). "Communication and collaboration in interdisciplinary research," in Enhancing Communication and Collaboration in Interdisciplinary Research, eds M. O'Rourke, S. Conway, S. Eigenbrode, and J. Wulfhorst (Los Angeles, CA: SAGE Publications), 11-39. doi: 10.4135/9781483352947.n2

Klein, J. T. (1990). Interdisciplinarity: History, Theory, and Practice. Detroit, MI: Wayne state university press.

Kosko, B. (1986). Fuzzy cognitive maps. Int. J. Man Mach. Stud. 24, 65-75.

Kozlowski, S. W. J., and Bell, B. S. (2019). "Evidence-based principles and strategies for optimizing team functioning and performance in science teams," in Strategies for Team Science Success, eds K. L. Hall, A. L. Vogel, and R. T. Croyle (Cham: Springer International Publishing), 269-293. doi: 10.1007/9783-030-20992-6_21

Krütli, P., Stauffacher, M., Flüeler, T., and Scholz, R. W. (2010). Functionaldynamic public participation in technological decision-making: site selection processes of nuclear waste repositories. J. Risk Res. 13, 861-875. doi: 10.1080/ 13669871003703252 
Lang, D. J., Wiek, A., Bergmann, M., Stauffacher, M., Martens, P., Moll, P., et al. (2012). Transdisciplinary research in sustainability science: practice, principles, and challenges. Sustain. Sci. 7, 25-43. doi: 10.1007/s11625-011-0149-x

Lemos, M. C., Arnott, J. C., Ardoin, N. M., Baja, K., Bednarek, A. T., Dewulf, A., et al. (2018). To co-produce or not to co-produce. Nat. Sustain. 1, 722-724.

Leslie, H. M., Basurto, X., Nenadovic, M., Sievanen, L., Cavanaugh, K. C., Cota-Nieto, J. J., et al. (2015). Operationalizing the social-ecological systems framework to assess sustainability. Proc. Natl. Acad. Sci. U.S.A. 112, 5979-5984.

Lewis, S. L., and Maslin, M. A. (2015). Defining the anthropocene. Nature 519, 171-180. doi: 10.1038/nature14258

Lubchenco, J., and Grorud-Colvert, K. (2015). Making waves: the science and politics of ocean protection. Science 350, 382-383. doi: $10.1126 /$ science.aad5443

Martone, R. G., Bodini, A., and Micheli, F. (2017). Identifying potential consequences of natural perturbations and management decisions on a coastal fishery social-ecological system using qualitative loop analysis. Ecol. Soc. 22:34. doi: 10.5751/ES-08825-220134

Mauser, W., Klepper, G., Rice, M., Schmalzbauer, B. S., Hackmann, H., Leemans, R., et al. (2013). Transdisciplinary global change research: the co-creation of knowledge for sustainability. Curr. Opin. Environ. Sustain. 5, 420-431. doi: 10.1016/j.cosust.2013.07.001

Melbourne-Thomas, J., Wotherspoon, S., Raymond, B., and Constable, A. (2012). Comprehensive evaluation of model uncertainty in qualitative network analyses. Ecol. Monogr. 82, 505-519. doi: 10.1890/12-0207.1

Micheli, F., Halpern, B. S., Botsford, L. W., and Warner, R. R. (2004). Trajectories and correlates of community change in no-take marine reserves. Ecol. Appl. 14, 1709-1723. doi: 10.1890/03-5260

National Academies of Sciences, Engineering, and Medicine (NASEM) (2018). Graduate STEM Education for the 21st Century. Washington, DC: The National Academies Press. doi: 10.17226/25038

National Research Council (2015). "Enhancing the effectiveness of team science. committee on the science of team science," in Board on Behavioral, Cognitive, and Sensory Sciences, Division of Behavioral and Social Sciences and Education, eds N. J. Cooke and M. L. Hilton (Washington, DC: The National Academies Press).

Nickols, K. J., White, J. W., Malone, D., Carr, M. H., Starr, R. M., Baskett, M. L., et al. (2019). Setting ecological expectations for adaptive management of marine protected areas. J. Appl. Ecol. 56, 2376-2385. doi: 10.1111/1365-2664.13463

Nurius, P. S., and Kemp, S. P. (2019). "Individual-level competencies for team collaboration with cross-disciplinary researchers and stakeholders," in Strategies for Team Science Success, eds K. L. Hall, A. L. Vogel, and R. T. Croyle (Cham: Springer International Publishing), 171-187. doi: 10.1007/978-3-030-20992-6_ 13

Oregon Ocean Policy Advisory Council (2008). Oregon Marine Reserve Policy Recommendations: A Report to the Governor, State Agencies and Local Governments from OPAC. Salem: OPAC.

O'Rourke, M., Crowley, S., Laursen, B., Robinson, B., and Vasko, S. E. (2019). "Disciplinary diversity in teams: integrative approaches from unidisciplinarity to transdisciplinarity," in Strategies for Team Science Success, eds K. L. Hall, A. L. Vogel, and R. T. Croyle (Cham: Springer International Publishing), 21-46. doi: 10.1007/978-3-030-20992-6_2

Ostrom, E. (2009). A general framework for analyzing sustainability of socialecological systems. Science 325, 419-422. doi: 10.1126/science.1172133

Pardo, J. C., Ramon, D., Stefanelli-Silva, G., Elegbede, I., Lima, L. S., and Principe, S. C. (2020). Advancing through the pandemic from the perspective of marine graduate researchers: challenges, solutions, and opportunities. Front. Mar. Sci. 7:528. doi: 10.3389/fmars.2020.00528

Pohl, C., and Hadorn, G. H. (2008). Methodological challenges of transdisciplinary research. Nat. Sci. Soc. 16, 111-121. doi: 10.1051/nss:2008035

Read, E. K., O’Rourke, M., Hong, G. S., Hanson, P. C., Winslow, L. A., Crowley, S., et al. (2016). Building the team for team science. Ecosphere 7:e01291.
Rittel, H. W., and Webber, M. M. (1973). Dilemmas in a general theory of planning. Policy Sci. 4, 155-169. doi: 10.1007/BF01405730

Rosenfield, P. L. (1992). The potential of transdisciplinary research for sustaining and extending linkages between the health and social sciences. Soc. Sci. Med. 35, 1343-1357. doi: 10.1016/0277-9536(92)90038-r

Stember, M. (1991). Advancing the social sciences through the interdisciplinary enterprise. Soc. Sci. J. 28, 1-14. doi: 10.1016/0362-3319(91) 90040-b

Stokols, D. (2014). "Training the next generation of transdisciplinarians," in Enhancing Communication \& Collaboration in Interdisciplinary Research, eds M. O’Rourke, S. Conway, S. Eigenbrode, and J. Wulfhorst (Los Angeles, CA: SAGE Publications), 56-81. doi: 10.4135/9781483352947.n4

Stokols, D., Hall, K. L., Taylor, B. K., and Moser, R. P. (2008). The science of team science: overview of the field and introduction to the supplement. Am. J. Prev. Med. 35, S77-S89. doi: 10.1016/j.amepre.2008.05.002

Stone, D. (2014). "Beyond common ground: a transdisciplinary approach to interdisciplinary communication and collaboration," in Enhancing Communication \& Collaboration in Interdisciplinary Research, eds M. O'Rourke, S. Crowley, S. D. Eigenbrode, and J. D. Wulfhorst (Thousand Oaks, CA: SAGE Publishing), 82-102. doi: 10.4135/9781483352 947.n5

Szoslak, R. (2014). "Communicating Complex Concepts," in Enhancing Communication \& Collaboration in Interdisciplinary Research, eds M. O’Rourke, S. Crowley, S. D. Eigenbrode, and J. D. Wulfhorst (Thousand Oaks, CA: SAGE Publishing), 34-55. doi: 10.4135/9781483352947.n3

Thomas, K. M., Willis, L. A., and Davis, J. (2007). Mentoring minority graduate students: issues and strategies for institutions, faculty, and students. Equal Oppor. Int 26, 178-192. doi: 10.1108/02610150710735471

Thompson, J. L. (2009). Building collective communication competence in interdisciplinary research teams. J. Appl. Commun. Res. 37, 278-297. doi: 10.1080/00909880903025911

Tress, B., Tres, G., Fry, G., and Opdam, P. (2005). From Landscape Research to Landscape Planning: Aspects of Integration, Education and Application. Berlin: Springer Science \& Business Media.

Tuckman, B. W. (1965). Developmental sequence in small groups. Psychol. Bull. 63, 384-399. doi: 10.1037/h0022100

United Nations (UN) (2015). Transforming Our World: The 2030 Agenda for Sustainable Development. Resolution Adopted by the General Assembly. Available online at: http://www.un.org/ga/search/view_doc.asp?symbol=A/ RES/70/1\&Lang=E (Accessed April 15, 2020).

Vasslides, J. M., and Jensen, O. P. (2016). Fuzzy cognitive mapping in support of integrated ecosystem assessments: developing a shared conceptual model among stakeholders. J. Environ. Manag. 166, 348-356. doi: 10.1016/j.jenvman. 2015.10.038

Yates, K. K., Turley, C., Hopkinson, B. M., Todgham, A. E., Cross, J. N., Greening, H., et al. (2015). Transdisciplinary science: a path to understanding the interactions among ocean acidification, ecosystems, and society. Oceanography 28, 212-225. doi: 10.5670/oceanog.2015.43

Conflict of Interest: The authors declare that the research was conducted in the absence of any commercial or financial relationships that could be construed as a potential conflict of interest.

Copyright (C) 2021 Wilson, Laufer, Howard and Wong-Ala. This is an open-access article distributed under the terms of the Creative Commons Attribution License (CC BY). The use, distribution or reproduction in other forums is permitted, provided the original author(s) and the copyright owner(s) are credited and that the original publication in this journal is cited, in accordance with accepted academic practice. No use, distribution or reproduction is permitted which does not comply with these terms. 